\title{
Caracterização do comportamento de pastas e argamassas de cimentos Portland durante o processo de lixiviação acelerada
}

\author{
P. G. Goulart ${ }^{1}$, R. P. Dias ${ }^{2 *}$, A. C. P. dos $\operatorname{Santos}^{3}$ \\ *rp.dias.2020@aluno.unila.edu.br \\ ${ }^{1}$ Graduando em Engenharia Civil de Infraestrutura, Universidade Federal da Integração Latino-Americana \\ (UNILA), Foz do Iguaçu, Brasil. \\ ${ }^{2}$ Mestranda em Engenharia Civil, Universidade Federal da Integração Latino-Americana (UNILA), bolsista CAPES, \\ Foz do Iguaçu, Brasil. \\ ${ }^{3}$ Doutora em Engenharia Civil, Professora adjunta na Universidade Federal da Integração Latino-Americana \\ (UNILA), Foz do Iguaçu, Brasil.
}

\begin{abstract}
RESUMO
Este artigo tem o objetivo de analisar o comportamento de cimentos com adições frente ao processo de lixiviação acelerada de pastas e argamassas fabricadas a partir de três cimentos brasileiros, estas foram expostas a uma solução agressiva de nitrato de amônio que potencializa a dissolução dos íons de cálcio, sendo realizados ensaios de compressão axial, termogravimetria, DRX, titulação química e avanço da lixiviação. Os resultados obtidos indicaram um melhor comportamento dos cimentos pozolânicos frente ao processo de lixiviação, apresentando menor queda de resistência à compressão Axial, menor avanço da frente de lixiviação e maior estabilidade da portlandita. Análises complementares estão sendo realizadas a fim de compreender a influência da relação $\mathrm{Ca} / \mathrm{Si}$ na lixiviação dos C-S-H.
\end{abstract}

Palavras-chave: Cimento Portland; Lixiviação; Durabilidade; Desempenho. 


\title{
RESUMEN
}

Este artículo tiene como objetivo analizar el comportamiento de los cementos con adiciones ante el proceso de lixiviación acelerada. Las pastas y morteros de tres cementos brasileños fueron expuestos a una solución agresiva de nitrato de amonio que favorece la disolución de los iones de calcio, realizándose ensayos de compresión axial, termogravimetría, XRD, titulación química y avance de lixiviación. Los resultados obtenidos indicaron un mejor comportamiento de los cementos puzolánicos en relación al proceso de lixiviación, con menor caída de resistencia a la compresión, menor avance del frente de lixiviación y mayor estabilidad de la portlandita. Se están llevando a cabo análisis complementarios para comprender la influencia de la relación $\mathrm{Ca} / \mathrm{Si}$ en la lixiviación de C-S-H.

Palabras clave: Cemento Portland; Lixiviación; Durabilidad; Desempeño.

\begin{abstract}
This paper aims to analyze the behavior of cements with additions in the face of the accelerated leaching process. Pastes and mortars made from three Brazilian cements were exposed to an aggressive ammonium nitrate solution that potentiates the dissolution of calcium ions, with compressive strength tests, thermogravimetry, XRD, chemical titration and leaching progress. The results obtained indicated a better behavior of the pozzolanic cements in relation to the leaching process, with less resistance drop, less advance of the leaching front and greater stability of portlandite. Complementary analyzes are being carried out in order to understand the influence of the $\mathrm{Ca} / \mathrm{Si}$ ratio on $\mathrm{C}-\mathrm{S}-\mathrm{H}$ leaching.
\end{abstract}

Keywords: Portland Cement; Leaching; Durability; Performance.

\section{INTRODUÇÃO}

A facilidade de utilização, baixo custo e alta resistência mecânica fazem do concreto o material fabricado mais consumido atualmente em todo o planeta, apresentando um crescimento exponencial em sua utilização nos últimos anos (Cancio Díaz et al., 2017; K. L. Scrivener et al., 2018). Em razão do principal componente do concreto ser o cimento, esse aumento na utilização de materiais cimentícios eleva as emissões de $\mathrm{CO}_{2}$ em virtude da alta pegada de carbono associada ao clínquer (Hossain et al., 2018; IEA, 2009). Para diminuir a emissão de $\mathrm{CO}_{2}$ e conferir determinadas propriedades necessárias para aplicações específicas, a indústria cimenteira passou a desenvolver novos cimentos a partir da utilização de materiais cimentícios suplementares (MCS). O Brasil possui atualmente 10 cimentos normatizados pela ABNT NBR 16697 (ABNT, 2018), sendo 9 deles possuidores de algum tipo de MCS, variando entre materiais carbonáticos, escória granulada de alto-forno e materiais pozolânicos.

A alteração da composição dos cimentos tem impacto em todas as características dos concretos produzidos, desde a cinética da hidratação até a composição dos produtos hidratados, sendo essa variação mais observada em cimentos pozolânicos (Lothenbach et al., 2011). Além do aumento das fases AFm e da Portlandita ser consumida em idades posteriores pela reação com os materiais silicosos ou sílico-aluminosos, os C-S-H formados a partir de cimentos pozolânicos possuem menores relações $\mathrm{Ca} / \mathrm{Si}$ e um aumento no teor de aluminato incorporado, influenciando as 
propriedades mecânicas e de durabilidade dos concretos e argamassas produzidos devido a interação da matriz cimentícia com os agentes agressivos (Cuesta et al., 2021; Dai et al., 2014). Apesar da água ser um elemento fundamental na produção de concretos e argamassas, o contato com a mesma pode causar a degradação por meio de alguns fenômenos, como a lixiviação. A mesma é caracterizada pelo aparecimento de precipitações brancas na superfície, conforme Figura 1, em virtude da dissolução e do transporte dos íons de cálcio dos compostos hidratados de uma matriz cimentícia quando em contato com o fluxo de água, principalmente as águas puras ou ácidas (Taylor, 1997). A velocidade de difusão e dissolução dos íons de cálcio é dependente do tamanho e da conectividade entre os poros, fazendo com que matrizes mais densas e com redes de poros menos interconectadas tendam a apresentar melhor resistência ao processo inicial de lixiviação (Rozière et al., 2009; Wan et al., 2015). Com o avanço do processo ocorre o aumento da porosidade e do coeficiente de difusão, fatores que combinados à degradação do concreto de superfície podem causar a despassivação do aço e maior propensão à corrosão das armaduras (Jia et al., 2019; Phung et al., 2016).
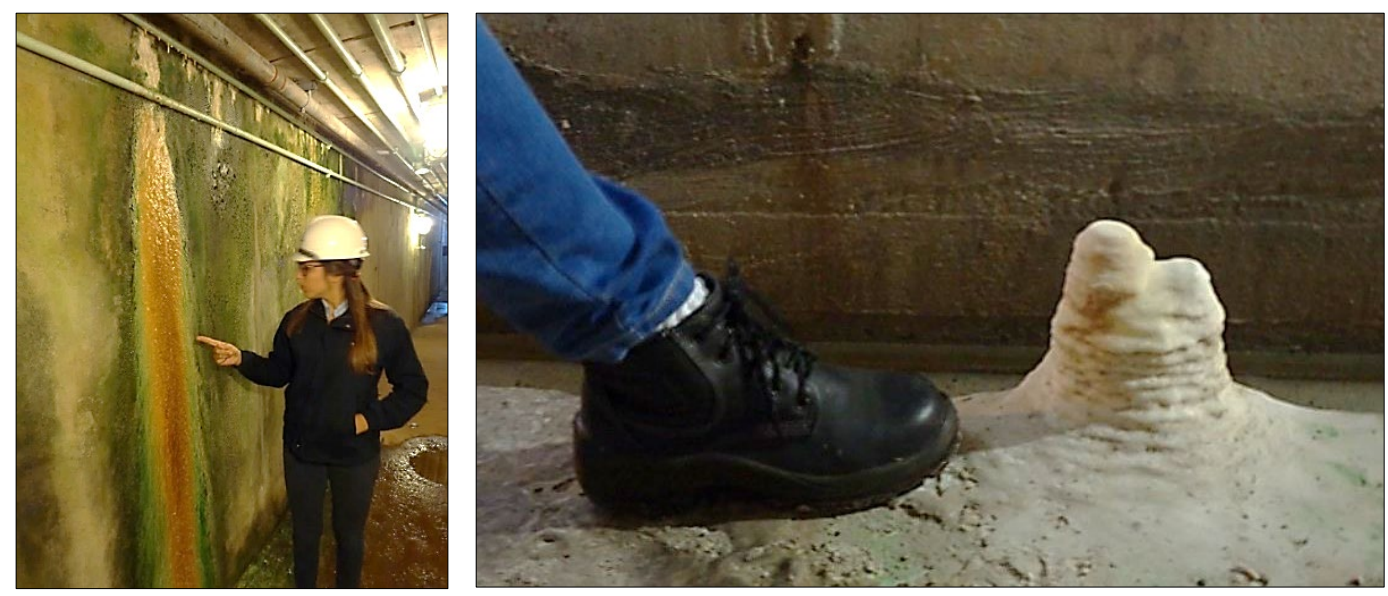

Figura 1. Exemplos de lixiviação em concreto massa na Usina Hidrelétrica (UH) de Itaipu (C. J. Neumann, 2019).

O fenômeno de lixiviação do cálcio tem sido relatado desde 1920, porém existem poucos registros sobre casos com danos severos em estruturas de concreto em virtude da lenta taxa de degradação quando comparada a outros fenômenos como a carbonatação e a reação álcali-agregado (Nakarai et al., 2006). Entretanto, esse ataque é muito observado em estruturas hidráulicas, como portos, pontes e barragens, onde o contato com a água é constante e a vida útil é superior às edificações convencionais, sendo necessárias análises mais criteriosas. Nesse sentido, Neumann (2019) avaliou o processo de lixiviação no concreto de enchimento da casa de força da Usina Hidrelétrica de Itaipu constatando que entre 1984 e 2019 3,4\% do total de cálcio existente na região passível de ser afetada havia sido perdido, valor considerado dentro dos limites estabelecidos durante a fase de concepção e projeto. Além disso, é importante ressaltar que o concreto desse local foi fabricado com a adição de cinza volante, conferindo pozolanicidade à mistura e, teoricamente, proporciona a mesma uma estrutura de poros mais refinada, podendo essa ser uma das razões para a boa resistência à lixiviação (C. Neumann et al., 2021).

Dessa maneira, a fim de contribuir no entendimento do processo de lixiviação, essa pesquisa teve como objetivo avaliar o processo de lixiviação acelerada em três cimentos brasileiros, sendo dois deles compostos por MCS de origens pozolânicas e outro apenas com a adição de filler calcário. Foram moldados corpos de prova (CP's) a partir de pastas e argamassas para a realização de ensaios de resistência à compressão, avanço da lixiviação, termogravimetria e DRX. 


\section{MATERIAIS E MÉTODOS}

\subsection{Materiais}

Foram utilizados três cimentos comerciais brasileiros com composições obtidas a partir de ensaios de FRX, conforme Tabela 1. De acordo com a ABNT NBR 16697 (ABNT, 2018), os três cimentos possuem diferentes níveis de adições de material carbonático e, além disso, o CP II-Z e o CP-IV contém adições pozolânicas.

Tabela 1. Resultados dos ensaios de FRX e granulometria a laser dos cimentos

\begin{tabular}{|c|c|c|c|}
\hline \multirow{2}{*}{ Composto } & \multicolumn{3}{|c|}{ \% em massa } \\
\hline & CP II-F & CP II-Z & CP IV \\
\hline $\mathrm{CaO}$ & 63.91 & 59.95 & 59.26 \\
\hline $\mathrm{SiO}_{2}$ & 12.67 & 18.63 & 21.66 \\
\hline $\mathrm{MgO}$ & 3.65 & 0.86 & 1.74 \\
\hline $\mathrm{SO}_{3}$ & 3.46 & 3.30 & 1.85 \\
\hline $\mathrm{Al}_{2} \mathrm{O}_{3}$ & 3.26 & 6.23 & 6.38 \\
\hline $\mathrm{Fe}_{2} \mathrm{O}_{3}$ & 2.99 & 3.19 & 2.72 \\
\hline $\mathrm{K}_{2} \mathrm{O}$ & 1.09 & 1.26 & 0.94 \\
\hline $\mathrm{TiO}_{2}$ & 0.21 & 0.36 & 0.36 \\
\hline $\mathrm{SrO}$ & 0.18 & 0.26 & 0.31 \\
\hline $\mathrm{BaO}$ & 0.14 & 0.00 & 0.00 \\
\hline $\mathrm{MnO}$ & 0.06 & 0.00 & 0.00 \\
\hline $\mathrm{ZnO}$ & 0.01 & 0.00 & 0.00 \\
\hline $\mathrm{CuO}$ & 0.01 & 0.00 & 0.00 \\
\hline Perda ao Fogo & 8.356 & 5.92 & 4.78 \\
\hline \multicolumn{4}{|c|}{ Granulometria $(\mu \mathrm{m})$} \\
\hline $\mathrm{D}_{\mathrm{V} .10}$ & 1.56 & 1.59 & 1.42 \\
\hline $\mathrm{D}_{\mathrm{v} .50}$ & 14.56 & 14.78 & 12.91 \\
\hline $\mathrm{D}_{\mathrm{v} .90}$ & 39.32 & 41.57 & 33.11 \\
\hline
\end{tabular}

A areia utilizada na produção das argamassas foi a areia normal brasileira nas frações grossa (\#16), média grossa (\#30), média fina (\#50) e fina (\#100). A mesma é produzida pelo Instituto de Pesquisas Tecnológicas (IPT) de acordo com a ABNT NBR 7214 (ABNT, 2015).

Foi utilizada uma Resina Epóxi Transparente 2001 (0.670 Kg) com Endurecedor 3154 (0.330 Kg), da marca Redelease, com a finalidade de isolar as laterais dos CP's (corpos de prova) para que o processo de degradação ocasionado pela lixiviação acelerada ocorresse apenas na direção axial dos mesmos.

Para a etapa de lixiviação, o agente agressivo utilizado foi o nitrato de amônio em solução de $2 \mathrm{~mol} / \mathrm{l}$. O nitrato de amônio é um composto químico inorgânico que possui fórmula química 
$\mathrm{NH}_{4} \mathrm{NO}_{3}$, peso molecular $80.04 \mathrm{~g} / \mathrm{mol}$ e, na concentração utilizada, proporciona uma aceleração do processo de lixiviação (Arribas et al., 2018).

\subsection{Moldagem e cura dos corpos de prova}

Foram preparadas argamassas com traço $1: 3: 0.55$ e moldados 15 CP's cilíndricos $(5 \mathrm{~cm}$ de diâmetro $\times 10 \mathrm{~cm}$ de altura) para ensaios de resistência à compressão (ABNT, 2019) e para a coleta de material para ensaios de termogravimetria; e $5 \mathrm{CP}$ 's cúbicos de $125 \mathrm{~cm}^{3}$ $(5 \mathrm{~cm} \times 5 \mathrm{~cm} \times 5 \mathrm{~cm})$ para a medição do avanço da lixiviação. Além disso, para evitar a influência da sílica presente na areia, foram preparadas pastas com relação água/cimento de 0.55 e moldados 5 CP's cúbicos de $1 \mathrm{~cm}^{3}(1 \mathrm{~cm} \times 1 \mathrm{~cm} \times 1 \mathrm{~cm})$ para ensaios de DRX.

Após a moldagem, todos os CP's permaneceram dentro dos moldes por 24 horas e depois foram submetidos a 270 dias de cura úmida em um tanque de imersão de água saturada com cal hidratada para evitar a perda de cálcio para o meio. O ensaio de lixiviação acelerada não é normatizado e o protocolo estabelecido inicialmente foi de uma cura de 90 dias, garantindo estado avançado das reações pozolânicas. Em virtude da impossibilidade de acesso aos laboratórios ocasionada pela pandemia do COVID-19, os CP's permaneceram por mais tempo em cura.

Após os 270 dias de cura úmida, os CP's foram submetidos a uma lavagem para remover o excesso de cal aderida à superfície dos mesmos e deixados em temperatura ambiente durante 24 horas para uma secagem completa. Após esse procedimento, as laterais dos CP's cilíndricos foram resinadas para permitir o avanço da lixiviação apenas na direção axial dos mesmos.

24 horas após o processo de resinagem, os CP's cilíndricos foram retificados para remover eventuais imperfeições que pudessem interferir no ensaio de resistência à compressão axial (ABNT, 2019).

\subsection{Processo de lixiviação acelerada e ensaios realizados}

O processo de lixiviação acelerada consiste na imersão dos corpos de prova em soluções de nitrato de amônio (concentração de 2 mols por litro) dentro de recipientes plásticos com tampa, com dimensões de $24 \mathrm{~cm} \mathrm{x} 40 \mathrm{~cm}$ x $16 \mathrm{~cm}$ (Figura 2), conforme metodologia proposta por Arribas et al. (2018). Para cada tipo de cimento foram preparados 7 litros de solução, quantidade suficiente para garantir a imersão total de todos os CP's. Os CP's de cada tipo de cimento foram dispostos em caixas plásticas distintas para evitar que amostras de diferentes composições químicas estivessem em contato com a mesma solução.

A etapa de coleta de dados foi realizada simultaneamente ao processo de lixiviação acelerada. Nas datas $0,1,3,7$, e 21 dias (contados a partir do início da imersão dos corpos de prova em solução lixiviante), foram coletados um CP cúbico para a medição do avanço da lixiviação por meio da aspersão da solução de fenolftaleína, $3 \mathrm{CP}$ 's cilíndricos para o ensaio de resistência à compressão axial e um CP cúbico de pasta para a realização dos ensaios de DRX. As amostras para os ensaios de termogravimetria foram coletadas a partir do CP cilíndrico rompido que apresentou resistência à compressão intermediária entre os 3 ensaiados na mesma data. 


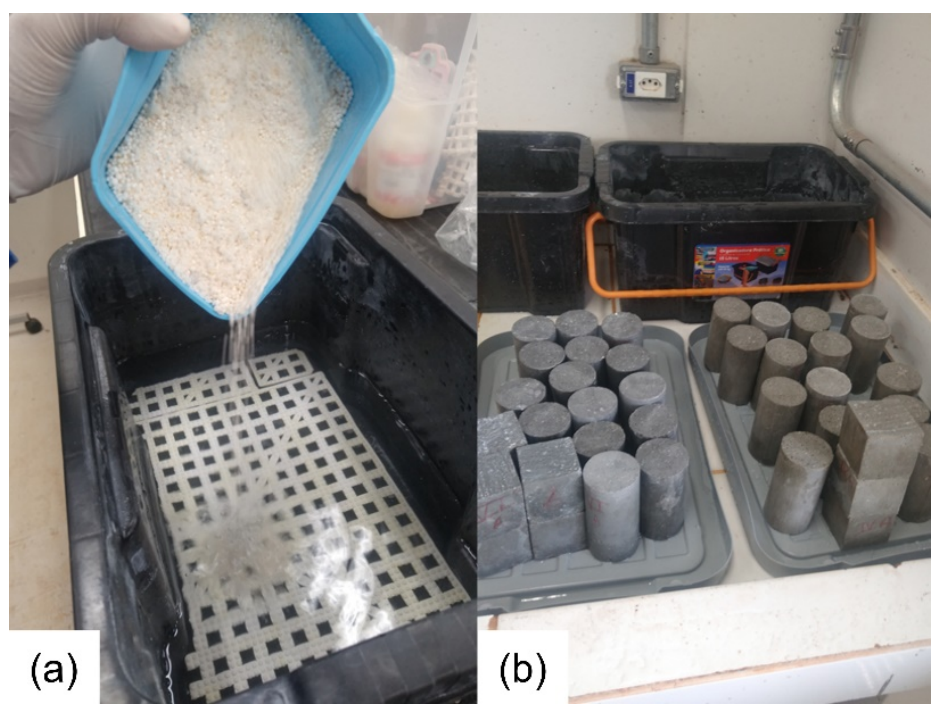

Figura 2. (a) Preparação da solução de nitrato de amônio e (b) corpos de prova antes do início do processo de lixiviação acelerada.

O ensaio de termogravimetria foi realizado em um equipamento STA 8000 (Perkins Elmer) com aquecimento da amostra a $35^{\circ} \mathrm{C}$ por 60 minutos para a evaporação da água livre e, posteriormente, uma rampa de aquecimento de $35{ }^{\circ} \mathrm{C}$ a $1000{ }^{\circ} \mathrm{C}$ a uma taxa de $10^{\circ} \mathrm{C} / \mathrm{min}$, sob atmosfera de nitrogênio com vazão de $20 \mathrm{ml} / \mathrm{min}$. A partir dos resultados do ensaio de termogravimetria e da Tabela 2 - elaborada a partir de resultados de pesquisas anteriores oriundas de parcerias com a Itaipu Binacional - os picos de perda da Portlandita $(\mathrm{CH})$ e carbonatos foram identificados.

Tabla 2. Faixas de temperatura consideradas para avaliação da TG (C. J. Neumann, 2019)

\begin{tabular}{|c|c|}
\hline Elemento & Faixa de temperatura \\
\hline $\mathrm{H}_{2} \mathrm{O}$ livre, parcelas de etringita e de C-S-H & $35^{\circ} \mathrm{C}$ a $150{ }^{\circ} \mathrm{C}$ \\
\hline $\mathrm{CaSO}_{4} \cdot 2 \mathrm{H}_{2} \mathrm{O}$ & $100^{\circ} \mathrm{C} \mathrm{a} 165^{\circ} \mathrm{C}$ \\
\hline Fases AFt (etringita) e AFm (monossulfatos) & $200{ }^{\circ} \mathrm{C} \mathrm{a} 400{ }^{\circ} \mathrm{C}$ \\
\hline Hidróxidos & $330{ }^{\circ} \mathrm{C} \mathrm{a} 500{ }^{\circ} \mathrm{C}$ \\
\hline Carbonatos & $600^{\circ} \mathrm{C} \mathrm{a} 800{ }^{\circ} \mathrm{C}$ \\
\hline
\end{tabular}

Para as análises de difratometria de raios-X (DRX) foi utilizado um difratômetro modelo PIXcel3D (Empyrean), com comprimento de onda $\mathrm{K} \alpha 1.5405$ (ânodo de cobre), 20, em intervalo de $5^{\circ}$ a $70^{\circ}$, 25 minutos de varredura, com base rotativa $(15 \mathrm{rpm})$, sob tensão de $40 \mathrm{kV}$ e corrente de $20 \mathrm{~A}$; a composição mineralógica dos materiais foi analisada com o software HighScore Plus da PANalytical BV de maneira qualitativa.

A análise da solução lixiviante consistiu na realização de titulação volumétrica da mesma utilizando a amostra da solução coletada, $\mathrm{NaOH}$ 5N (Hidróxido de Sódio com concentração de 5 normal) para a estabilização do pH da solução, EDTA (Ácido Etilenodiamino Tetra-acético) com concentração de $0,025 \mathrm{Mol} / \mathrm{L}$ como o reagente titulador e o indicador Murexida preparado com $\mathrm{NaCl}$ (Cloreto de Sódio) para estabilizar a reação e determinar o ponto de total complexação do $\mathrm{CaOH}$. O processo de titulação foi realizado nas mesmas idades que os demais ensaios. 


\section{RESULTADOS}

\subsection{Resistência à compressão}

Os resultados dos ensaios de resistência à compressão estão representados na Figura 3. Inicialmente já é possível visualizar que após os 270 dias de cura, a reação pozolânica dos cimentos CP II-Z e CP IV já está em estado avançado, ultrapassando a resistência à compressão da argamassa fabricada a partir de CP II-F em 40,5\% e 8,5\%, respectivamente.

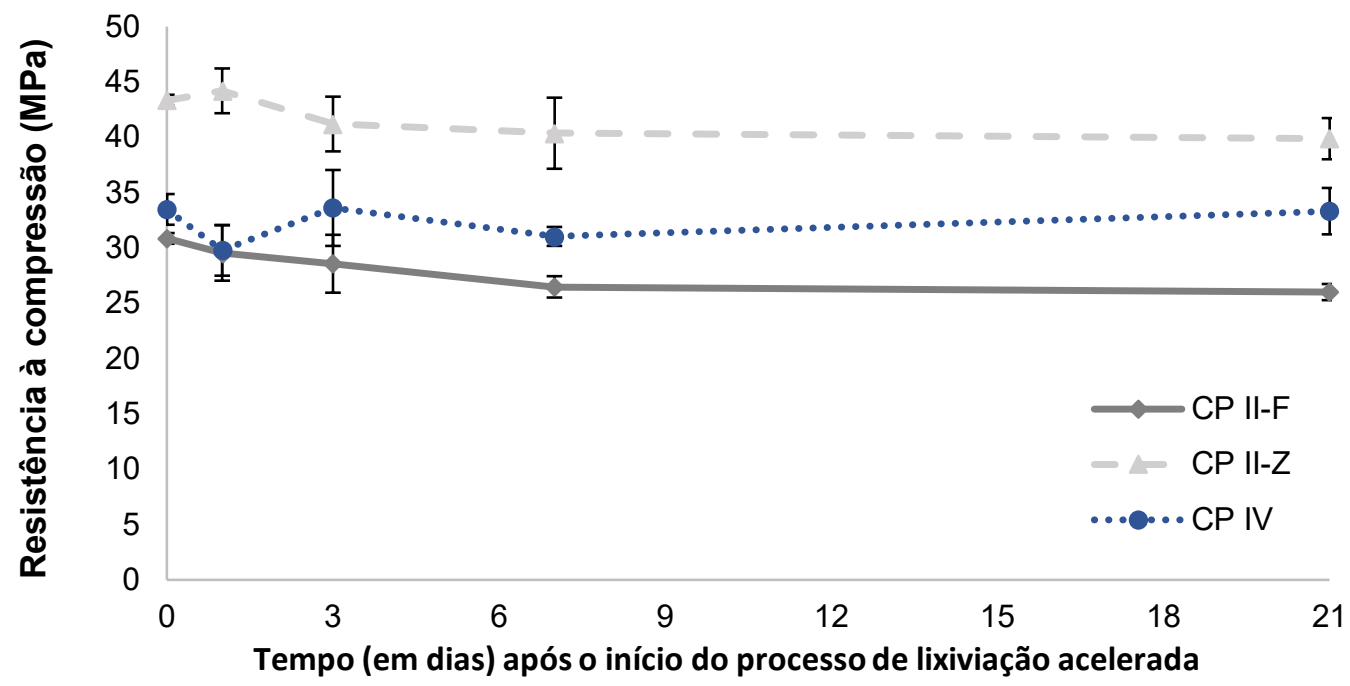

Figura 3. Resistências à compressão

Além de possuir menor resistência à compressão inicial, o CP II-F apresentou 15,7\% de queda na resistência mecânica após os 21 dias de lixiviação acelerada, maior percentual de decaimento entre os três cimentos avaliados. O CP II-Z apresentou uma queda na resistência à compressão de aproximadamente $8 \%$ enquanto o CP IV se manteve praticamente estável, corroborando os resultados de Jiang et al. (2021), que obtiveram redução da resistência à compressão na ordem de 4,5\% - 8\% para cimentos com diferentes teores de substituições pozolânicas. Arribas et al. (2018) também realizaram estudos de lixiviação acelerada (solução de nitrato de amônio com concentração de $6 \mathrm{~mol} / \mathrm{l}$ ), porém o período de cura foi de apenas 28 dias e a redução de resistência à compressão foi de aproximadamente $85 \%$.

Ademais, não é possível analisar questões acerca da porosidade de cada um dos cimentos e nem do tipo e teor de adições pozolânicas presentes no CP II-Z e no CP IV, mas os resultados de resistência à compressão indicam maior resistência à lixiviação dos cimentos pozolânicos.

\subsection{Avanço da Lixiviação}

A partir das medições realizadas com o paquímetro (Figura 4) foi possível verificar que o CP II-F apresentou maior avanço da lixiviação dentre os três cimentos avaliados, conforme Figura 5. Aos 21 dias, o processo de lixiviação atingiu aproximadamente $29.5 \%, 26.6 \%$ e $24.7 \%$ da área da seção transversal média dos $\mathrm{CP}^{\prime}$ s cúbicos das argamassas produzidas com CP II-F, CP IV e CP II-Z respectivamente. Os resultados vêm de encontro ao observado por Jiang et al. (2021), que constatou que quanto maior a presença de adições pozolânicas, menor o avanço da lixiviação. 
O cimento CP II-F apresentou maior avanço da lixiviação nas primeiras idades com $13.58 \%$ da área da seção transversal lixiviada após um dia de exposição ao agente agressivo. Esse valor corresponde, provavelmente, à lixiviação do hidróxido de cálcio, produto menos presente nos outros dois cimentos em virtude da presença de pozolanas.

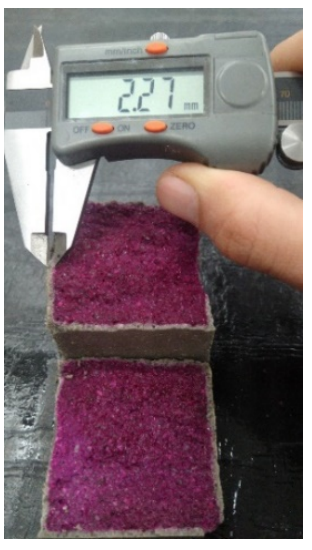

Figura 4. Medição do avanço da lixiviação

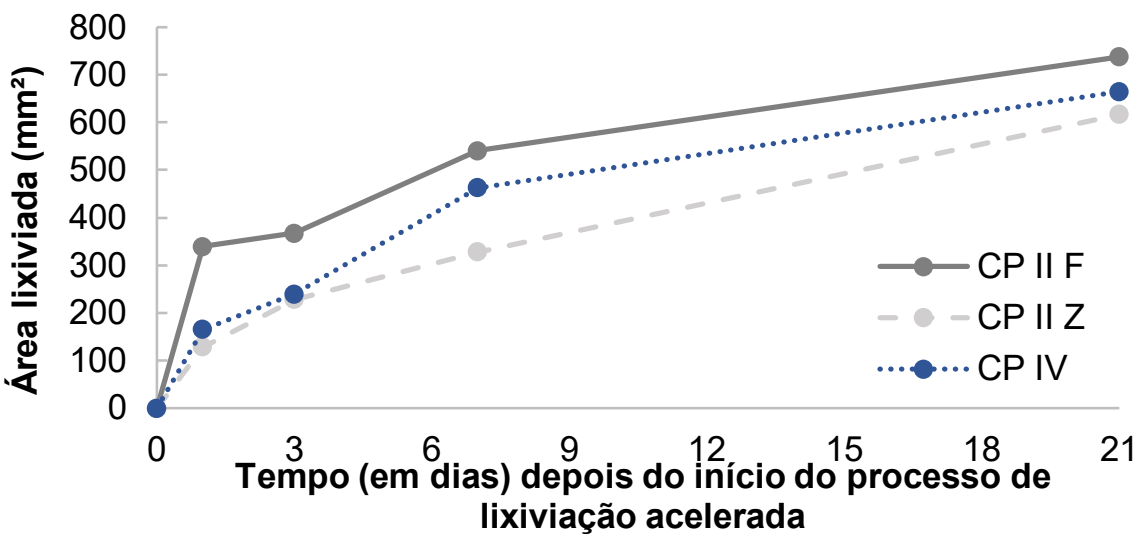

Figura 5. Área lixiviada

Apesar do CP II-F ter apresentado áreas lixiviadas superiores às dos outros cimentos em todas as idades de ensaio, a partir dos sete dias a taxa de avanço da lixiviação nos cimentos pozolânicos se iguala à taxa do cimento CP II-F. Isso pode ser um indicativo que após a lixiviação das estruturas da portlandita do CP II-F, a frente de lixiviação passa a acarrear os íons de cálcio das estruturas de C-S-H, apresentando, dessa maneira, um avanço uniforme e paralelo ao avanço da lixiviação dos cimentos pozolânicos em virtude da menor presença da Portlandita no CP II-Z e no CP IV, que, por ventura, possuem o início da lixiviação das estruturas de C-S-H antes do CP II-F.

\subsection{Termogravimetria e DRX}

Apesar de não ser possível obter as composições exatas dos cimentos, a Figura 6 ajuda a identificar algumas das fases presentes no dia 0 (condição inicial, 270 dias de cura, sem serem submetidos à solução lixiviante) e a fazer alguns comparativos entre os mesmos, visto que nenhuma normalização foi realizada. O CP IV possivelmente possuía maior teor de adição pozolânica em razão da menor quantidade de hidróxido de cálcio $(\mathrm{CH})$. 


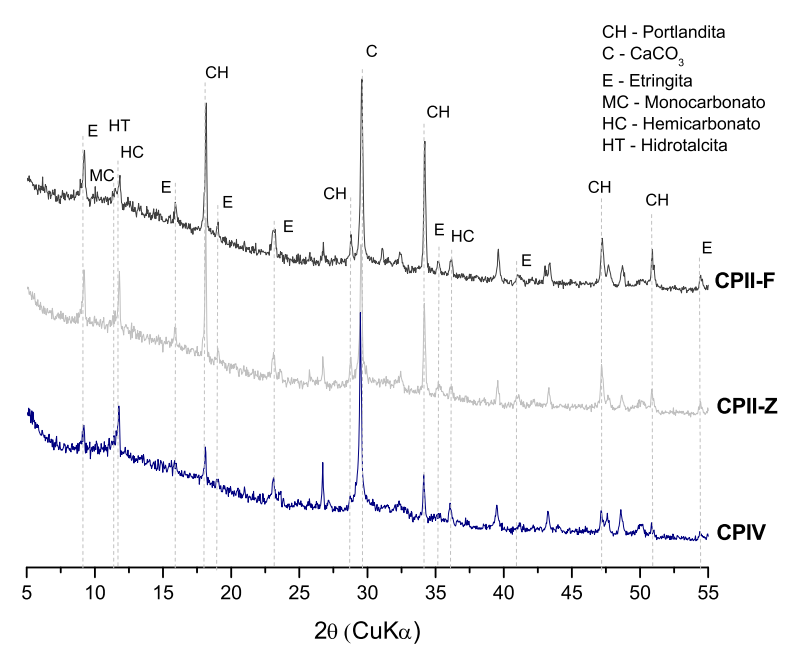

Figura 6. Difratogramas das pastas no dia 0 (270 dias de cura úmida).

As demais comparações foram realizadas apenas entre os cimentos, conforme Figura 7. Nenhuma normalização foi realizada pois não se pode afirmar que algum dos produtos hidratados não sofrerá alteração quando em contato com a solução lixiviante.
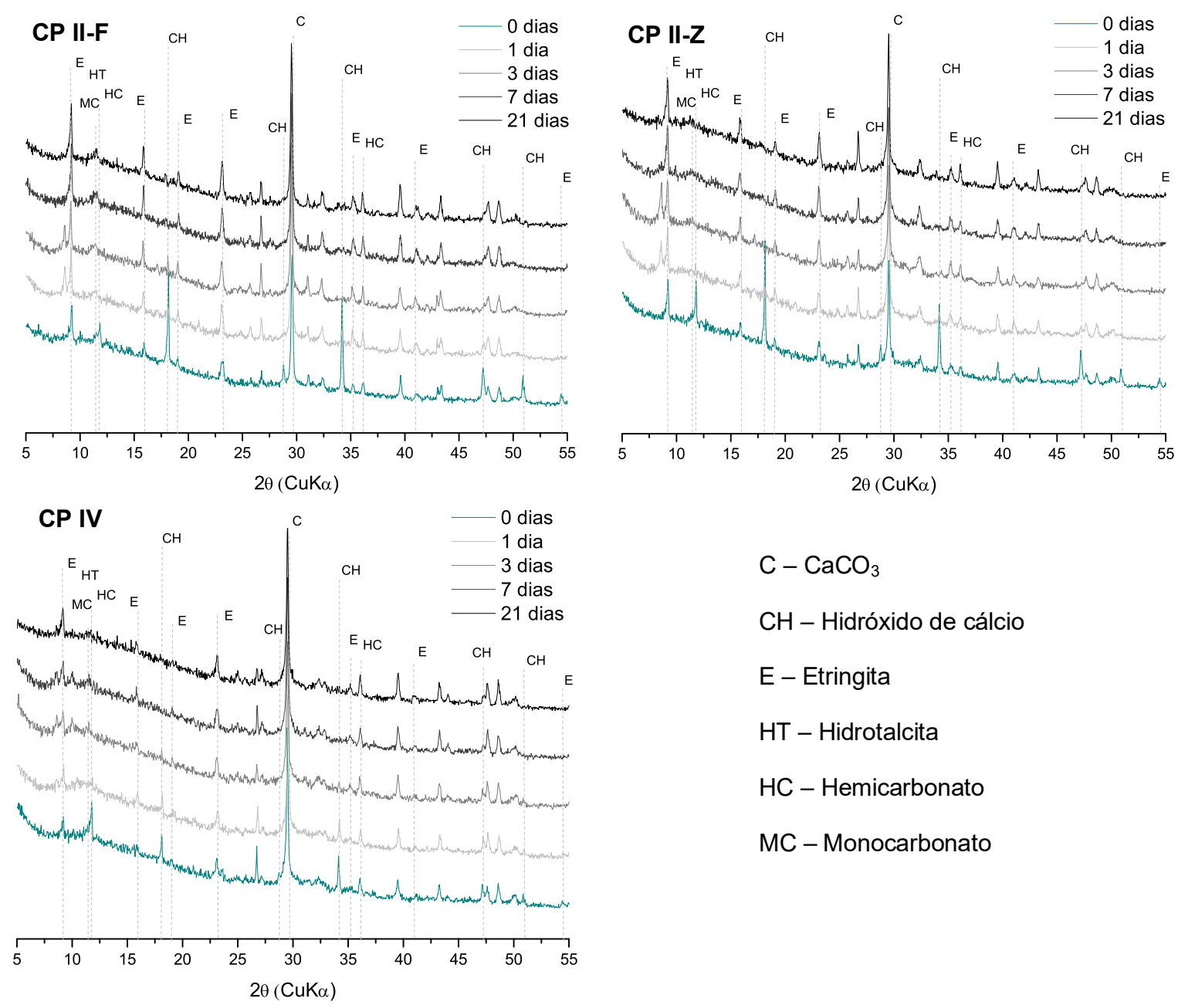

$$
\begin{aligned}
& \mathrm{C}-\mathrm{CaCO}_{3} \\
& \mathrm{CH} \text { - Hidróxido de cálcio } \\
& \mathrm{E} \text { - Etringita } \\
& \mathrm{HT} \text { - Hidrotalcita } \\
& \mathrm{HC} \text { - Hemicarbonato } \\
& \mathrm{MC} \text { - Monocarbonato }
\end{aligned}
$$

Figura 7. Difratogramas de todas as pastas. 
Os difratogramas representam basicamente a mudança das fases ao longo dos 21 dias de exposição à solução lixiviante. A principal mudança é no hidróxido de cálcio $\left(\mathrm{Ca}(\mathrm{OH})_{2}\right)$, que já apresentou uma queda brusca com 1 dia de exposição no CP II-F e CP II-Z. Apesar de o CP IV possuir menor teor de hidróxido de cálcio no dia 0 , a taxa de lixiviação aparenta ter sido menor com esse cimento. Ainda que a etringita seja considerada solúvel em contato com soluções lixiviantes, a mesma se mostrou mais estável que as demais fases cristalinas apontadas na Figura 7, assim como também apontado por Garcia-Lodeiro et al. (2021).

Partindo da análise comparativa obtida por meio dos ensaios de DRX, uma análise quantitativa foi realizada por meio dos resultados das curvas de TGA/DTG (Figura 8). Em uma primeira análise das curvas de DTG é possível verificar o pico de hidróxido de cálcio apenas no dia 0 , indicando um consumo muito rápido do mesmo pelo processo de lixiviação.

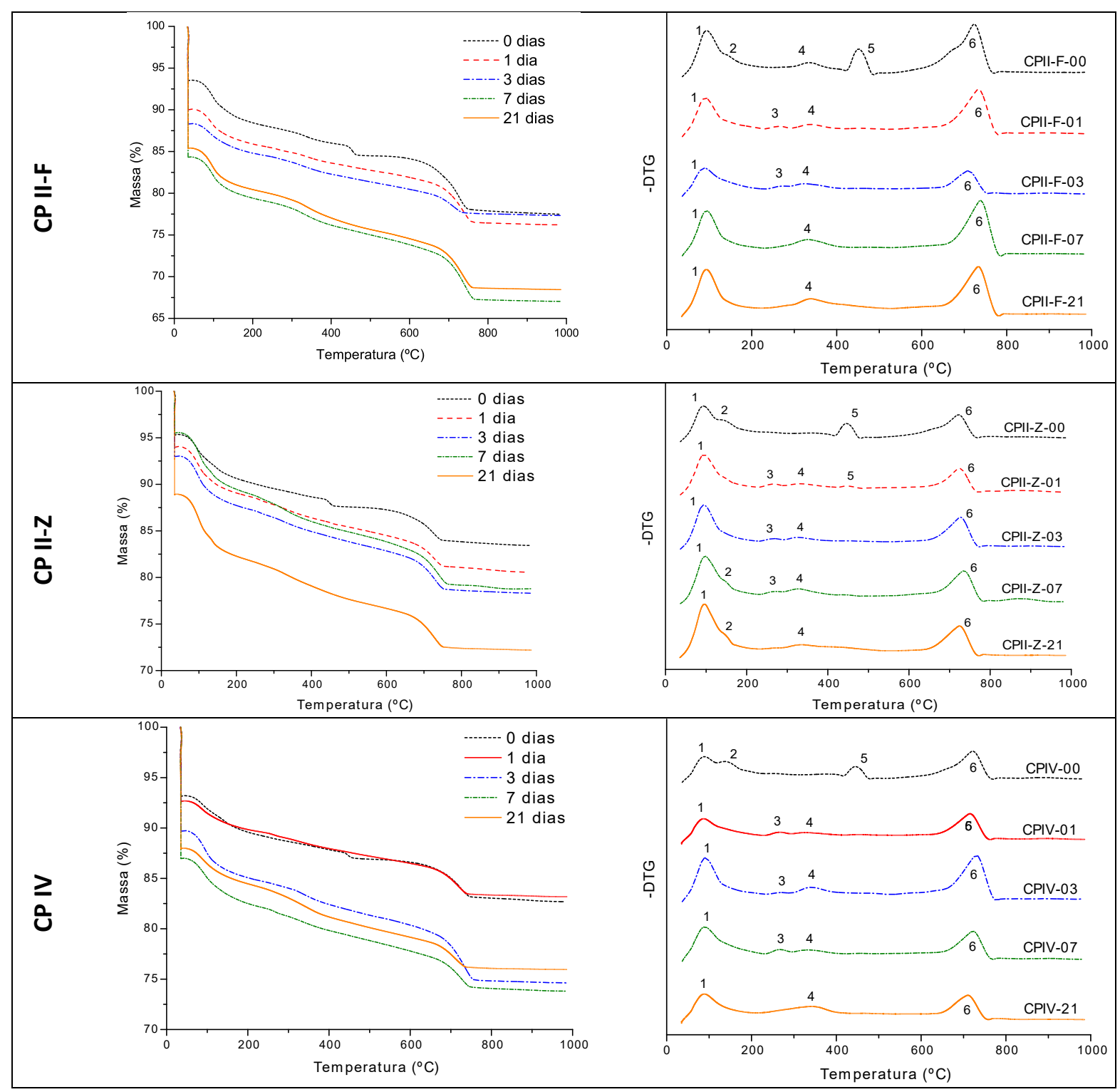

*OBS: Os picos observados no DTG são referentes a: $1-\mathrm{H}_{2} \mathrm{O}$, C-S-H e Etringita; 2 - Mono e Hemicarboaluminatos; 3 e 4 - Hidrotalcita; 5 - Portlandita; 6 - Carbonatos.

Figura 8. Curvas de TGA/DTG. 
Por meio das Equações (1) e (2) propostas por Scrivener et al. (2018) é possível estimar as massas de hidróxido de cálcio $\left(\mathrm{Ca}(\mathrm{OH})_{2}\right)$ e de carbonatos $\left(\mathrm{CaCO}_{3}\right)$, respectivamente. Os resultados estão representados nas Figuras 9 e 10.

$$
\begin{aligned}
& \mathrm{Ca}(\mathrm{OH})_{2, \text { calculado }}=\frac{\text { Perda de massa de Ca }(\mathrm{OH})_{2} \times \text { massa molecular } \mathrm{Ca}(\mathrm{OH})_{2}}{\text { massa molecular } \mathrm{H}_{2} \mathrm{O}} \\
& \mathrm{CaCO}_{3, \text { calculado }}=\frac{\text { Perda de massa de CaCO} \mathrm{C}_{3} \times \text { massa molecular CaCO}}{\text { massa molecular } \mathrm{CO}_{2}}
\end{aligned}
$$

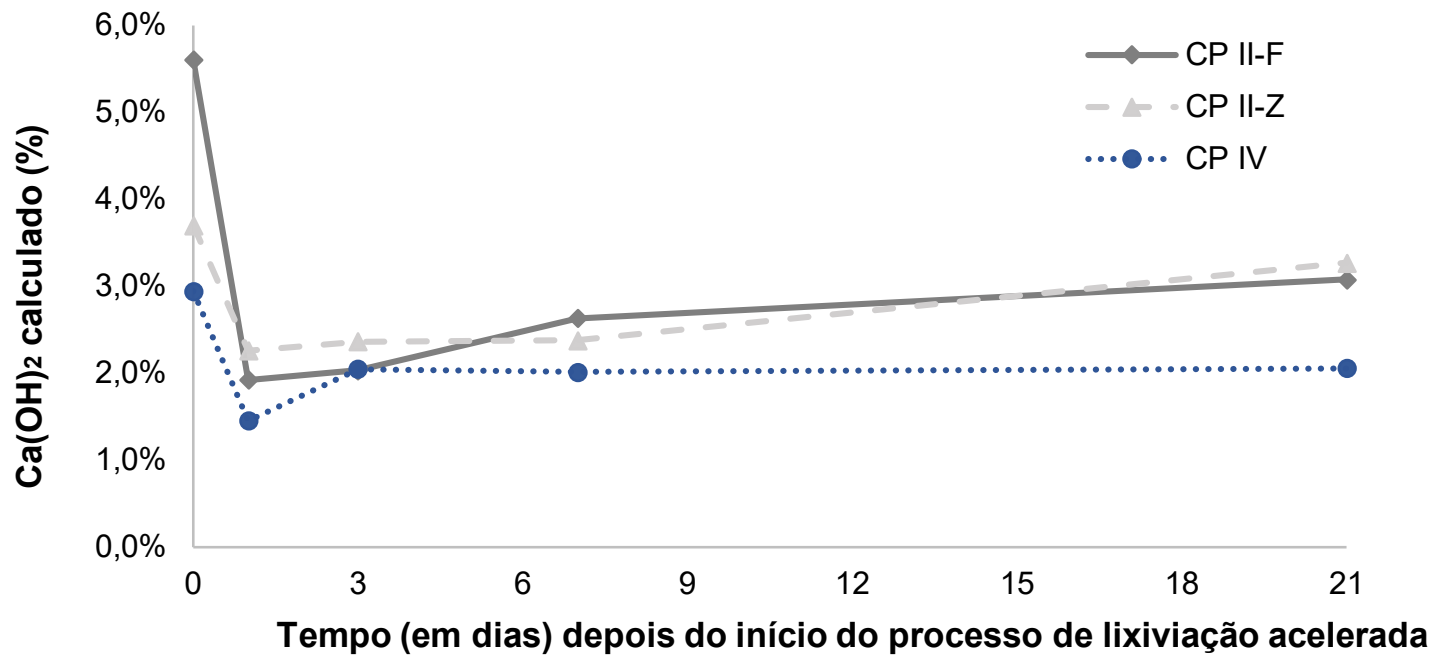

Figura 9. Massa calculada de hidróxido de cálcio $(\mathrm{CH})$ entre $424{ }^{\circ} \mathrm{C}$ e $475^{\circ} \mathrm{C}$.

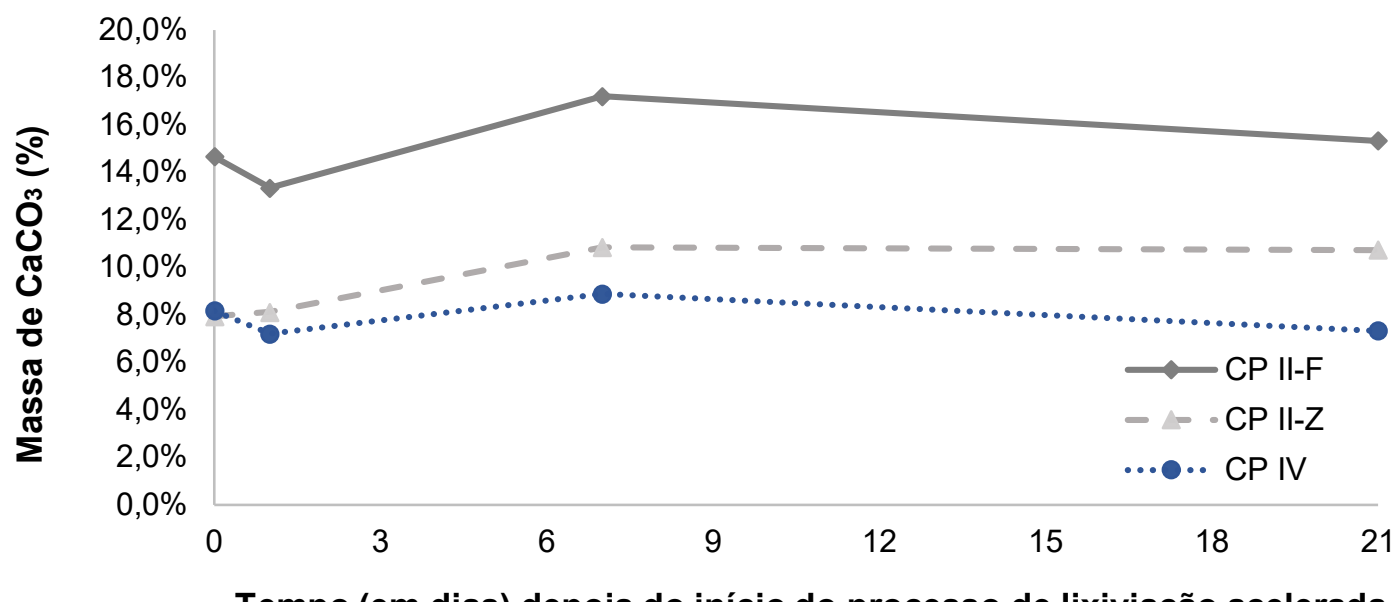

Figura 10. Massa calculada de carbonato de cálcio $\left(\mathrm{CaCO}_{3}\right)$ entre $599^{\circ} \mathrm{C}$ e $764^{\circ} \mathrm{C}$. 
Ao se analisar as perdas de massa calculadas a partir das equações de Scrivener et al. (2018), pode-se observar que em um dia de lixiviação a solução agressiva degradou praticamente todo o CH lixiviável (Figura 9), concluindo o estágio inicial da lixiviação descrito por Feng et al. (Feng et al., 2014), o qual é determinado pela diluição dos íons de cálcio, álcali e hidroxila ocasionando a dissolução da portlandita $(\mathrm{CH})$, assim como observado por Garcia Lodeiro et al. (2021). Esta, em excesso, tampona os poros, minimizando assim a dissolução de quaisquer outras fases sólidas presentes na matriz cimentícia. No entanto, assim que o $\mathrm{CH}$ se dissolve por completo, este não consegue mais interromper a lixiviação do C-S-H e outras estruturas, dando início assim a fase intermediaria, onde o $\mathrm{pH}$ da solução diminui e a descalcificação do C-S-H é iniciada. A quantificação desse processo ainda está em análise pois a faixa de temperatura onde os C-S-H são identificados na termogravimetria é compartilhada pela etringita e pela água livre (Tabela 2).

A massa de carbonatos se mostrou praticamente constante para os três cimentos analisados (Figura 10), indicando que os íons de cálcio dessas estruturas ainda não foram carreadas pelo processo de lixiviação (Feng et al., 2014). Os corpos de prova permaneceram submersos sem o contato com o $\mathrm{CO}_{2}$ da atmosfera, fazendo com que não fosse possível a formação de carbonatos por meio da reação de carbonatação com a atmosfera $\left(\mathrm{Ca}+\mathrm{CO}_{2} \rightarrow \mathrm{CaCO}_{3}\right)$, entretanto os picos do Hemicarbonato, Monocarbonato e Hidrotalcita se alteram com o decorrer dos dias (Figura 7), podendo indicar a ação do processo de lixiviação nessas estruturas.

\subsection{Quantificação do cálcio por titulação química}

Por meio da metodologia de titulação química, o cálcio na solução foi quantificado e está representado na Figura 11. Durante o primeiro dia, os cimentos com adição de Pozolana apresentaram maior quantidade de cálcio extraído da matriz cimentícia em comparação ao cimento sem esta adição, 0.66 g/l do CP II-Z e $1.64 \%$ do CP IV contra 0.39 g/l do CP II-F, comportamento anormal quando comparado às análises de termogravimetria e avanço da lixiviação. Mais investigações com respeito aos C-S-H formados e sua relação $\mathrm{Ca} / \mathrm{Si}$ estão em andamento.

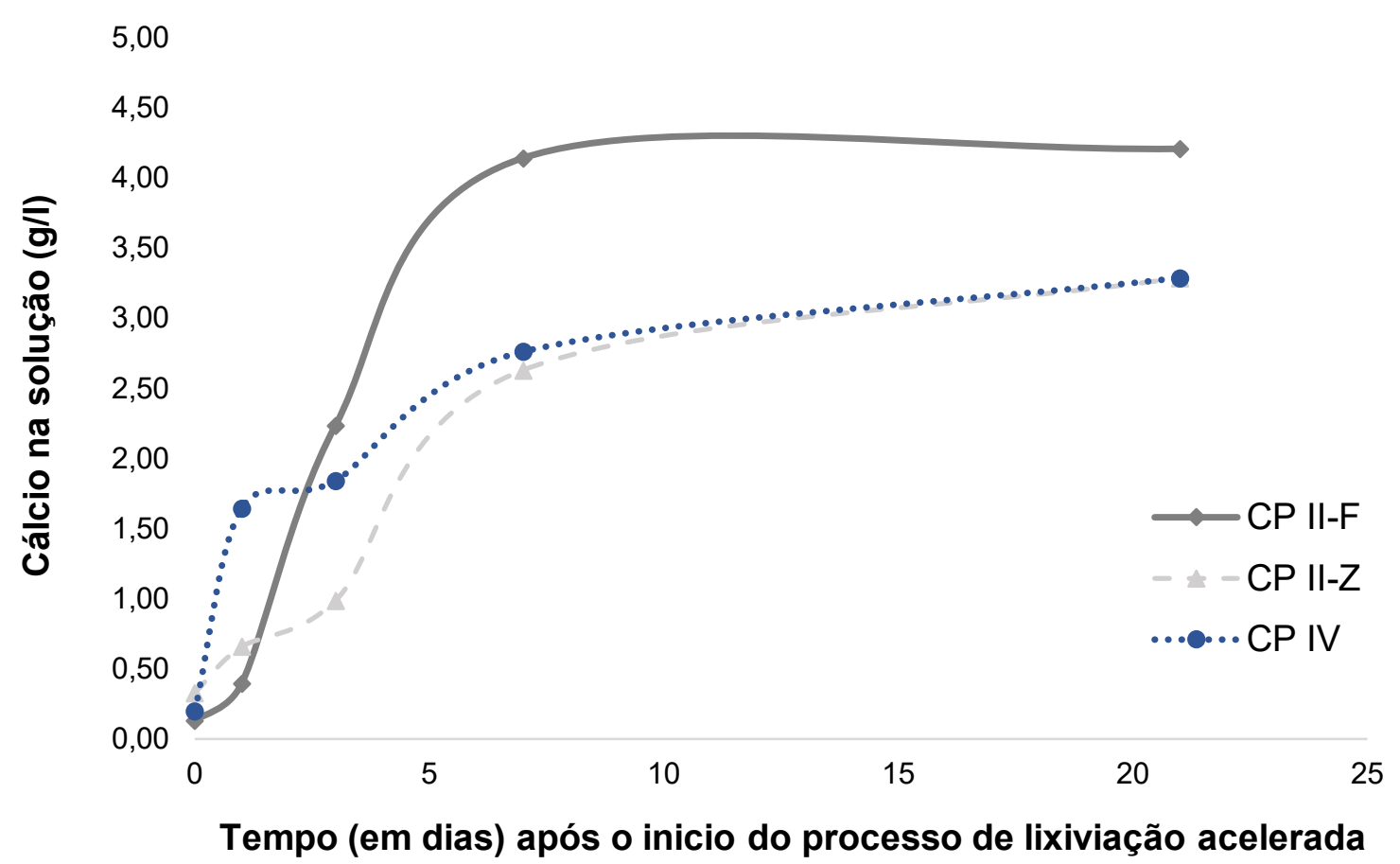

Figura 11. Massa calculada de cálcio na solução por meio do processo de titulação química. 
Após o primeiro dia o cimento CP II-F passa a apresentar maior quantidade de cálcio em solução $(2.24 \mathrm{~g} / \mathrm{l})$, indicando maior quantidade de cálcio lixiviado. Essa taxa crescente entre o dia 1 e 7 no CP II-F pode ser atribuída ao consumo da Portlandita, fase inicial da lixiviação (Feng et al., 2014). Após o consumo da portlandita, a próxima estrutura a ser lixiviada é o $\mathrm{C}-\mathrm{S}-\mathrm{H}$, possuindo uma taxa mais lenta do que quando comparada a portlandita.

\section{CONCLUSÕES}

Com base nos resultados obtidos até o momento é possível concluir que a presença de materiais pozolânicos é benéfica frente ao processo de lixiviação, minimizando o avanço da mesma e causando menores impactos nas propriedades resistentes. Além disso, esses cimentos são recomendados para grandes estruturas - como pontes e barragens - por apresentarem menor calor de hidratação e, muitas vezes, níveis mais baixos de $\mathrm{C}_{3} \mathrm{~A}$, reduzindo o risco de ataque de sulfato. Embora a caracterização química por FRX tenha sido realizada, as indústrias de cimento no Brasil não são obrigadas a relatar a real composição do cimento, impossibilitando análises mais específicas a respeito do teor e tipo de adições.

Ademais, ressalta-se que as informações apresentadas nesse documento são resultados parciais, tendo em andamento análises mais específicas com respeito a quantificação da relação $\mathrm{Ca} / \mathrm{Si}$ dos C-S-H e da alteração da morfologia dos produtos hidratados com o decorrer do processo de lixiviação.

\section{AGRADECIMENTOS}

Os autores agradecem à Itaipu e ao Centro de Estudos Avançados em Segurança de Barragens (CEASB) pelo apoio e financiamento de materiais, à Innova pelo apoio a pesquisa cientifica com a doação do reagente nitrato de amônio e à Unila e à CAPES pelas bolsas fornecidas aos discentes envolvidos. Os ensaios foram realizados no Laboratório de Desempenho, Estruturas e Materiais (LADEMA), Laboratório de Caracterização (LACAR) e no Laboratório Interdisciplinar de Ciências Físicas (LICT).

\section{REFERÊNCIAS}

Arribas, I., Vegas, I., García, V., Vigil de la Villa, R., Martínez-Ramírez, S., \& Frías, M. (2018). The deterioration and environmental impact of binary cements containing thermally activated coal mining waste due to calcium leaching. Journal of Cleaner Production, 183, 887-897. https://doi.org/10.1016/j.jclepro.2018.02.127

Associação Brasileira de Normas Técnicas. (2015). ABNT NBR 7214: Areia normal para ensaio de cimento - Especificação.

Associação Brasileira de Normas Técnicas. (2018). ABNT NBR 16697: Cimento Portland Requisitos.

Associação Brasileira de Normas Técnicas. (2019). ABNT NBR 7215: Cimento Portland Determinação da resistência à compressão de corpos de prova cilíndricos Portland. 
Cancio Díaz, Y., Sánchez Berriel, S., Heierli, U., Favier, A. R., Sánchez Machado, I. R., Scrivener, K. L., Martirena Hernández, J. F., \& Habert, G. (2017). Limestone calcined clay cement as a low-carbon solution to meet expanding cement demand in emerging economies. Development Engineering, 2(May 2016), 82-91. https://doi.org/10.1016/j.deveng.2017.06.001

Cuesta, A., Santacruz, I., De la Torre, A. G., Dapiaggi, M., Zea-Garcia, J. D., \& Aranda, M. A. G. (2021). Local structure and $\mathrm{Ca} / \mathrm{Si}$ ratio in $\mathrm{C}-\mathrm{S}-\mathrm{H}$ gels from hydration of blends of tricalcium silicate and silica fume. Cement and Concrete Research, 143(March), 106405. https://doi.org/10.1016/j.cemconres.2021.106405

Dai, Z., Tran, T. T., \& Skibsted, J. (2014). Aluminum incorporation in the C-S-H phase of white portland cement-metakaolin blends studied by $27 \mathrm{Al}$ and 29 Si MAS NMR spectroscopy. Journal of the American Ceramic Society, 97(8), 2662-2671. https://doi.org/10.1111/jace.13006

Feng, P., Miao, C., \& Bullard, J. W. (2014). A model of phase stability, microstructure and properties during leaching of portland cement binders. Cement and Concrete Composites, 49, 919. https://doi.org/10.1016/j.cemconcomp.2014.01.006

Garcia-Lodeiro, I., Goracci, G., Dolado, J. S., \& Blanco-Varela, M. T. (2021). Mineralogical and microstructural alterations in a portland cement paste after an accelerated decalcification process. Cement and Concrete Research, 140, 106312. https://doi.org/10.1016/j.cemconres.2020.106312

Hossain, M. U., Poon, C. S., Dong, Y. H., \& Xuan, D. (2018). Evaluation of environmental impact distribution methods for supplementary cementitious materials. Renewable and Sustainable Energy Reviews, 82(September 2017), 597-608.

https://doi.org/10.1016/j.rser.2017.09.048

IEA. (2009). Cement Technology Roadmap 2009 - Carbon emissions reductions up to 2050 (p. 36).

Jia, Z., Cao, R., Chen, C., \& Zhang, Y. (2019). Using in-situ observation to understand the leaching behavior of Portland cement and alkali-activated slag pastes. Composites Part B: Engineering, 177(August), 107366. https://doi.org/10.1016/j.compositesb.2019.107366

Jiang, C., Jiang, L., Tang, X., Gong, J., \& Chu, H. (2021). Impact of calcium leaching on mechanical and physical behaviors of high belite cement pastes. Construction and Building Materials, 286, 122983. https://doi.org/10.1016/j.conbuildmat.2021.122983

Lothenbach, B., Scrivener, K., \& Hooton, R. D. (2011). Supplementary cementitious materials. Cement and Concrete Research, 41(12), 1244-1256.

https://doi.org/10.1016/j.cemconres.2010.12.001

Nakarai, K., Ishida, T., \& Maekawa, K. (2006). Modeling of calcium leaching from cement hydrates coupled with micro-pore formation. Journal of Advanced Concrete Technology, 4(3), 395-407. https://doi.org/10.3151/jact.4.395

Neumann, C., Faria, E. F., \& dos Santos, A. C. P. (2021). Concrete leaching of a hydroelectric powerhouse due to 40 years of exposure to river water. Construction and Building Materials, 302(May), 124253. https://doi.org/10.1016/j.conbuildmat.2021.124253 
Neumann, C. J. (2019). Avaliação do processo de lixiviação em concreto massa - O caso de Itaipu Binacional. Universidade Federal da Integração Latino-Americana.

Phung, Q. T., Maes, N., Jacques, D., Perko, J., De Schutter, G., \& Ye, G. (2016). Modelling the evolution of microstructure and transport properties of cement pastes under conditions of accelerated leaching. Construction and Building Materials, 115, 179-192.

https://doi.org/10.1016/j.conbuildmat.2016.04.049

Rozière, E., Loukili, A., El Hachem, R., \& Grondin, F. (2009). Durability of concrete exposed to leaching and external sulphate attacks. Cement and Concrete Research, 39(12), 1188-1198. https://doi.org/10.1016/j.cemconres.2009.07.021

Scrivener, K. L., John, V. M., \& Gartner, E. M. (2018). Eco-efficient cements: Potential economically viable solutions for a low-CO2 cement-based materials industry. Cement and Concrete Research, 114(March), 2-26. https://doi.org/10.1016/j.cemconres.2018.03.015

Scrivener, K., Snellings, R., \& Lothenbach, B. (2018). A Practical Guide to Microstructural Analysis of Cementitious Materials. In A Practical Guide to Microstructural Analysis of Cementitious Materials. CRC Press. https://doi.org/10.1201/b19074

Taylor, H. F. W. (1997). Cement Chemistry (Second Edi). Thomas Telford Publishing. https://doi.org/doi:10.1680/cc.25929

Wan, K., Li, L., Xu, Q., \& Sun, W. (2015). Spatial distribution of the increased porosity of cement paste due to calcium leaching. Journal Wuhan University of Technology, Materials Science Edition, 30(4), 735-744. https://doi.org/10.1007/s11595-015-1221-7 